\title{
Neuropathic pain and use of PainDETECT in patients with fibromyalgia: a cohort study
}

\author{
Jarno Gauffin ${ }^{1 *}$, Tiina Hankama ${ }^{2 \dagger}$, Hannu Kautiainen ${ }^{3,4}$, Pekka Hannonen ${ }^{2,5}$ and Maija Haanpää ${ }^{6,7}$
}

\begin{abstract}
Backround: Fibromyalgia has a plethorae of symptoms, which can be confusing and even misleading. Accurate evaluation is necessary when patients with fibromyalgia are treated. Different types of instruments are available for the clinicians to supplement evaluation. Our objective was to study the applicability of the PainDETECT instrument to screen neuropathic pain in patients with fibromyalgia.

Methods: 158 patients with primary fibromyalgia underwent a neurological examination including bedside sensory testing. They also fulfilled four questionnaires: PainDETECT, Beck depression inventory IA (BDI IA), Fibromyalgia Impact Questionnaire (FIQ) and a self-made questionnaire regarding present pain and pain relieving methods of the patients. The results of the clinical evaluation and questionnaires were then compared.

Results: Clinically verified neuropathic pain was diagnosed in 53/158 [34\% (95\% Cl: 26 to 41)] patients. The ROC curve achieved a maximum Youden's index at score of 17 when sensitivity was 0.79 (95\% Cl: 0.66 to 0.89) and specificity 0.53 ( $95 \% \mathrm{Cl}: 0.43$ to 0.63 ). The PainDETECT total score (OR: $1.1495 \% \mathrm{Cl}: 1.06$ to 1.22 ), FM as the worst current pain (OR: 0.31; 95\% 0.16 to 0.62), body mass index (BMI) (OR: 1.05; 95\% Cl: 1.00 to 1.11) and the intensity of current pain (OR: 1.20; $95 \% \mathrm{Cl}: 1.01$ to 1.41) were significantly associated with the presence of neuropathic pain in univariate analyses.
\end{abstract}

Conclusion: This study highlights the importance of thorough clinical examination. The Neuropathic pain screening tool PainDETECT is not as useful in patients with fibromyalgia as in patients with uncompromised central pain control.

\section{Background}

Fibromyalgia (FM) is a chronic pain syndrome, which affects up to $5 \%$ of the general population [1]. Characteristic features of FM are widespread musculoskeletal pain and tenderness as well as fatigue in the absence of any explanatory organic disease [2]. Other usual symptoms are disturbed sleep, cognitive problems and a variety of psychosomatic symptoms originating from various organs [3]. Patients with FM often complain also about tingling, numbness, burning pain, cutaneous hyperalgesia, and pain attacks [4], which are typical symptoms of neuropathic pain. The IASP (International Association for Study of Pain) defined neuropathic pain recently as "pain caused by a lesion or disease of the somatosensory system" [5]. The prevalence of neuropathic pain in the general population is poorly known. Two

\footnotetext{
* Correspondence: jarno.gauffin@orton.fi

${ }^{\dagger}$ Equal contributors

'ORTON Rehabilitation Centre, ORTON Foundation, Helsinki, Finland

Full list of author information is available at the end of the article
}

population-based studies from Europe reported the prevalence of pain predominantly of neuropathic origin [6] or pain with neuropathic characteristics [7] to be $8 \%$ and $7 \%$, respectively when assessed with a screening questionnaire without clinical confirmation of the diagnosis. According to a population-based study, the prevalence of neuropathic pain is around $10 \%$ in citizens aged 30 years or older [8].

Neuropathic pain screening tools such as PainDETECT are recommended for identifying patients with suspected neuropathic pain, particularly when used by non-specialists $[9,10]$. Baron et al. [11] also showed that PainDETECT is useful for identifying different sensory profiles of neuropathic pain when a neuropathic pain condition (e.g. diabetic neuropathy or postherpetic neuralgia) has already been diagnosed. PainDETECT, which was developed and validated in Germany, incorporates a self-report questionnaire with 9 items [12]. There are 7 weighted sensory descriptor items and 2 items relating to the spatial (radiating)

\section{Biomed Central}


and temporal characteristics of the individual pain pattern. Its sensitivity and specificity compared to clinical diagnosis is $85 \%$ and $80 \%$, respectively. PainDETECT was initially developed and validated in patients with back pain but has shown applicability also to patients with other types of neuropatic pain. When using PainDETECT for screening purposes Freynhagen et al. [12] found cut-off scores $\leq$ 12 (a neuropathic component is unlikely) and $\geq 19$ (a neuropathic component is likely) to be most appropriate. PainDETECT has been translated into several languages, including Finnish.

In this study we report the applicability of the PainDETECT tool to screen neuropathic pain in patients with fibromyalgia (FM).

\section{Methods}

\section{Patients}

Participants for the study were recruited from the patients with FM who had been diagnosed and treated in outpatient departments of Rheumatology or Physical medicine and rehabilitation of Jyväskylä Central Hospital between 2006 and 2008. Patients were identified using the ICD-10 code M79.0 according to the 2006 version. Based on medical records, patients with previously diagnosed neuropathic pain or neuropathy, active inflammatory arthritis, systemic connective tissue disease, cognitive impairment, severe psychiatric disorders (e.g., psychotic disorder, major depression, or severe anxiety disorder diagnosed by a psychiatrist) or any other unstable disease (e.g., cancer) were excluded. Only patients aged 18-65 years were included.

\section{Data collection}

The questionnaires and consent form were sent to all traceable patients. The patients were asked to fill in four questionnaires: (1) PainDETECT [12], (2) Beck depression inventory IA (BDI IA) [13], (3) Fibromyalgia Impact Questionnaire (FIQ) [14], and (4) a one-page self-made questionnaire. Beck depression inventory IA is a 21-item questionnaire to assess possible depression and it is validated in Finnish [15]. FIQ is a multidimensional selfadministered questionnaire including 10 questions, which evaluate physical functioning, work status, depression, anxiety, sleep, pain, stiffness, fatigue and well-being. It is also validated in Finnish [16]. The self-made questionnaire included questions regarding the pain condition of the patients, the intensity of their current pain, the effect of their pain relief methods, and the rank of FM pain compared to other possible pains.

Those who replied were invited to a clinical visit, where an experienced physician $(\mathrm{TH})$ examined the patients and confirmed the diagnosis of FM according to the criteria of the American College of Rheumatology [17]. Based on careful clinical history and physical examination, including neurological examination with meticulous bedside sensory testing, she also assessed whether the patient had neuropathic pain or not [18]. The level of certainty of the neuropathic pain diagnosis was graded as definite, probable or possible [19]. The grading system has four items: 1 . Pain with a distinct neuroanatomically plausible distribution. 2. History suggestive of a relevant lesion or disease affecting the peripheral or central somatosensory system. 3. Demonstration of the distinct neuroanatomically plausible distribution by at least one test. And 4. Demonstration of the relevant lesion or disease by at least one test. The definite grade requires all items 1 . to 4 . The probable grade requires items 1 . and 2. plus either 3 . or 4 . The possible grade requires items 1 . and 2 .

\section{Statistical methods}

Results were expressed as means with standard deviation (SD) and 95\% confidence intervals (CIs), and as medians with interquartile range (IQR). Statistical comparison between the groups was performed by t-test, permutation test or Chi-square test, when appropriate. Relationships between neuropathic pain and important risk factors were analyzed with univariate and multivariate forward stepwise logistic regression models. Receiver operating characteristic (ROC) curve was constructed to determine the cut-off point of PainDETECT that corresponds to the clinically verified neuropathic pain, with bias corrected bootstrap CIs. Values for the area under the ROC curve from 0.7 to 0.8 indicate reasonable discrimination and values exceeding 0.8 indicate good discrimination. We defined the best cut-off value as the value with the highest accuracy that maximizes the Youden's index. Sensitivity, specificity, positive predictive value, likelihood ratio, Youden's index, and their 95\% CI values were calculated.

\section{Ethical aspects}

The study protocol was approved by The Committee of Research Ethics of Central Finland Health Care District, and the patients gave their informed consent in writing.

\section{Results}

The postal survey was mailed to 239 patients with primary FM, and 169 patients (71\%) replied. Five patients declined to attend the clinical visit due to long distances. Six patients had filled in questionnaires insufficiently and were excluded from the analyses. Hence 158 patients who had undergone clinical evaluation and had completed the questionnaires adequately were included in the analyses. All of them fulfilled the diagnostic criteria of primary FM. In addition to FM, clinically verified neuropathic pain was diagnosed in 53/158 [34\% (95\% Cl: 26 to 41)] patients. Neuropathic pain was definite in 16 
Table 1 Demographic and clinical data of 158 FM patients with and without neuropathic pain diagnosis

\begin{tabular}{llll}
\hline Variables & $\mathbf{N P}$ & $\mathbf{N N P}$ & P-value \\
& $\mathbf{N}=\mathbf{5 3}$ & $\mathbf{N = 1 0 5}$ & \\
\hline Females, number (\%) & $49(92)$ & $100(95)$ & 0.48 \\
Age, mean (SD) & $49(8)$ & $46(12)$ & 0.074 \\
BMI, mean (SD) & $29.6(6.6)$ & $27.3(6.6)$ & 0.041 \\
Duration of diagnosis, median (IQR) & $4(2.7)$ & $3(2.8)$ & 0.53 \\
FIQ, mean (SD) & $52.3(19.4)$ & $48.0(20.1)$ & 0.19 \\
PainDETECT score, mean (SD) & $19.8(5.0)$ & $15.9(5.8)$ & $<0.001$ \\
Beck Depression Inventory, & $14.4(7.2)$ & $13.5(9.4)$ & 0.57 \\
mean (SD) & & & \\
Efficacy of pain relief*, mean (SD) & $6.3(1.7)$ & $6.8(1.8)$ & 0.13 \\
Health score**, mean (SD) & $5.8(2.1)$ & $5.8(2.0)$ & 0.95 \\
Current pain intensity***, mean (SD) & $6.3(2.0)$ & $5.6(2.2)$ & 0.033 \\
Number of patients with FM pain as & $22(41)$ & $73(70)$ & $<0.001$ \\
their worst current pain (\%) & & & \\
\hline
\end{tabular}

$\mathrm{NP}=$ neuropathic pain, $\mathrm{NNP}=$ non-neuropathic pain, $\mathrm{BMI}=$ body mass index, $\mathrm{FIQ}=$ Fibromyalgia Impact Questionnaire.

*Expressed as numerical rating scale $(0=$ no pain relief, $10=$ maximal pain relief).

** Expressed as numerical rating scale $(0=$ poor health, $10=$ maximal state of health).

*** Expressed as numerical rating scale $(0=$ no pain, $10=$ worst imaginable pain)

(10\%) patients, probable in $30(19 \%)$ patients and possible in 7 (4\%) patients. The PainDETECT score and the intensity of current pain were significantly higher in the patients with neuropathic pain compared to those without it. FM pain was regarded as the worst current pain in $70 \%$ of the patients without neuropathic pain and in $41 \%$ of the patients with neuropathic pain $(\mathrm{p}<0.001)$ (Table 1, Figure 1). The neuropathic pain diagnoses of the 46 patients with definite or probable neuropathic pain are listed in Table 2.

The ROC curve achieved a maximum Youden's index at score of 17 when sensitivity was 0.79 (95\% Cl: 0.66 to 0.89 ) and specificity 0.53 (95\% $\mathrm{Cl}: 0.43$ to 0.63$)$. The area under the curve was $0.69(95 \% \mathrm{Cl}: 0.60$ to 0.77$)$. The predictive value of a positive test and likelihood ratio (positive) were 0.46 (95\% Cl: 0.36 to 0.57 ) and 1.7 (95\% Cl: 1.33 to 2.17 ) respectively (Table 3 , Figure 2 ).

The PainDETECT total score (OR: 1.14 95\% Cl: 1.06 to 1.22 ), FM as the worst current pain (OR: $0.31 ; 95 \%$ 0.16 to 0.62 ), body mass index (BMI) (OR: $1.05 ; 95 \% \mathrm{Cl}$ : 1.00 to 1.11 ) and the intensity of current pain (OR: 1.20; 95\% Cl: 1.01 to 1.41 ) were significantly associated with the presence of neuropathic pain in univariate analyses. The PainDETECT score and the patient's own assessment of FM pain as their worst pain entered into the forward logistic regression model (Table 4).

\section{Discussion}

Our main finding showed that PainDETECT cannot distinguish neuropathic pain from non-neuropathic pain in FM patients. In the PainDETECT validation study a cutoff value of 19 points had both sensitivity and specificity of 0.84 [12], whereas that cut-off value reached sensitivity of 0.59 and specificity of 0.67 in our cohort. In our study the optimal cut-off value was 17 points with sensitivity of 0.79 and a low specificity of 0.53 . The PainDETECT score and FM as the worst current pain had the strongest association with the presence of neuropathic pain, the latter having negative association, i.e., FM pain as the worst current pain proved to be a protective marker to neuropathic pain. Based on these results of sensitivity and specificity we do not recommend the use of PainDETECT for

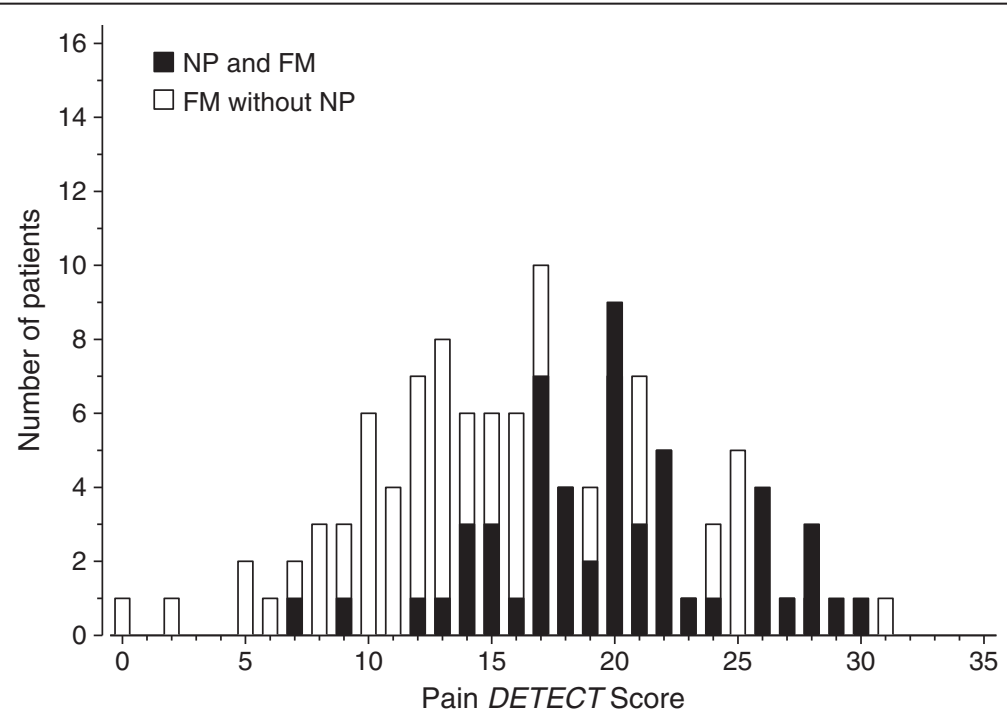

Figure 1 Distribution of the PainDETECT scores according to the presence or absence of neuropathic pain diagnosis in FM patients. 
Table 2 Neuropathic pain diagnoses in 46 patients with probable or definite neuropathic pain

\begin{tabular}{|c|c|c|c|}
\hline NP diagnoses & $\begin{array}{l}\text { Probable } \\
\text { NP N }=30\end{array}$ & $\begin{array}{l}\text { Definite } \\
\text { NP N = } 16\end{array}$ & $\begin{array}{l}\text { Method(s) of } \\
\text { confirming } \\
\text { definite NP } \\
\text { diagnosis }\end{array}$ \\
\hline Lumbar radiculopathy & 20 & 8 & $\begin{array}{l}\text { ENMG (4), } \\
\text { lumbar MRI (4 }\end{array}$ \\
\hline Thoracic radiculopathy & 1 & & \\
\hline Cervical radiculopathy & 2 & 1 & cervical MRI \\
\hline Painful polyneuropathy & 0 & 2 & $\begin{array}{l}\text { ENMG (2), } \\
\text { gene test* (1) }\end{array}$ \\
\hline $\begin{array}{l}\text { Peripheral nerve } \\
\text { entrapment \# }\end{array}$ & 4 & 3 & ENMG \\
\hline $\begin{array}{l}\text { Peripheral nerve } \\
\text { lesion a }\end{array}$ & 3 & 2 & ENMG \\
\hline
\end{tabular}

$\mathrm{NP}=$ neuropathic pain.

* confirming the diagnosis of hereditary polyneuropathy.

\# compression of median nerve in 3 and ulnar nerve in 2, tarsal tunnel syndrome in 1.

a lesion of peroneal nerve 2, ulnar nerve in 1, cervical plexus in 1 and trigeminal nerve in 1.

patients with FM as the principal diagnostic tool. It is worth noting that FM patients were excluded from the validation studies of PainDETECT [12] and DN4 (another neuropathic pain screening tool) [20]. Likewise patients with "mixed pain" were excluded from the validation study of LANSS [21]. A recent review recommended that neuropathic pain screening tools should not be used for patients with widespread pain [22]. Although neuropathic pain screening tools have not been validated with FM patients, Rhem et al. [4] and Koroschetz et al. [23] used PainDETECT to classify FM patients on the basis of their sensory symptoms. On the basis of LANSS results in FM patients Martinez-Lavin et al. [24] even suggested that FM might be a neuropathic pain state.

Although patients with previously diagnosed neuropathic pain were excluded, and therefore the prevalence

Table 3 Characteristics with 95 per cent confidence intervals of performance of different PainDETECT cut-off scores

\begin{tabular}{llll}
\hline Characteristics & \multicolumn{3}{c}{ PainDETECT screening } \\
\cline { 2 - 4 } & \multicolumn{3}{c}{ Cut-off score } \\
\cline { 2 - 4 } & $\mathbf{1 2}$ & $\mathbf{1 7}$ & $\mathbf{1 9}$ \\
\hline Sensitivity & $0.94(0.84$ & $0.79(0.43$ & $0.58(0.44$ \\
& to 0.99$)$ & to 0.89$)$ & to 0.72$)$ \\
Specificity & $0.29(0.20$ & $0.53(0.43$ & $0.67(0.57$ \\
& to 0.38$)$ & to 0.63$)$ & to 0.76$)$ \\
Predictive value of & $0.40(0.31$ & $0.46(0.36$ & $0.47(0.35$ \\
positive test & to 0.49$)$ & to 0.57$)$ & to 0.60 \\
Likelihood ratio (positive) & $1.32(1.14$ & $1.70(1.33$ & $1.75(1.23$ \\
& to 1.53$)$ & to 2.17$)$ & to 2.50$)$ \\
Youden's index & $0.23(0.13$ & $0.33(0.17$ & $0.25(0.08$ \\
& to 0.33$)$ & to 0.47$)$ & to 0.41$)$ \\
\hline
\end{tabular}

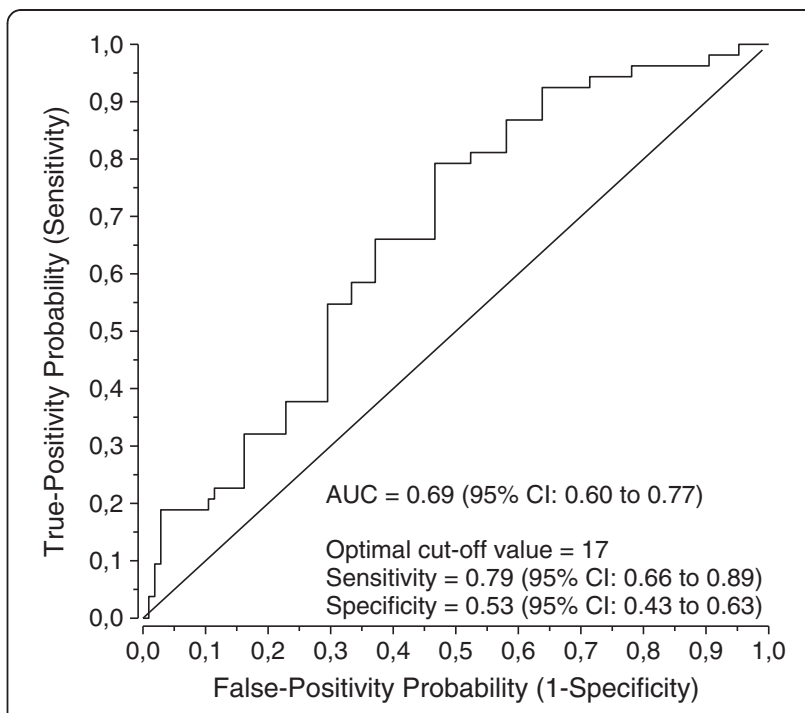

Figure 2 ROC curve of PainDETECT scores when used to define the presence of neuropathic pain.

Table 4 Logistic regression models for the odds to presence of neuropathic pain in FM patients

\begin{tabular}{|c|c|c|c|c|}
\hline Variable & $\begin{array}{l}\text { Univariate } \\
\text { OR }(95 \% \mathrm{CI})\end{array}$ & $P$ value & $\begin{array}{l}\text { Multivariate* } \\
\text { OR }(95 \% \mathrm{Cl})\end{array}$ & $P$ value \\
\hline Female gender & $\begin{array}{l}0.61(0.16 \\
\text { to } 2.38)\end{array}$ & 0.48 & & \\
\hline Age & $\begin{array}{l}1.03(1.00 \\
\text { to } 1.07)\end{array}$ & 0.076 & & \\
\hline Body mass index & $\begin{array}{l}1.05(1.00 \\
\text { to } 1.11)\end{array}$ & 0.048 & & \\
\hline $\begin{array}{l}\text { Duration of } \\
\text { fibromyalgia } \\
\text { diagnosis }\end{array}$ & $\begin{array}{l}1.02(.96 \\
\text { to } 1.08)\end{array}$ & 0.59 & & \\
\hline $\mathrm{FIQ}$ & $\begin{array}{l}1.12(.94 \\
\text { to } 1.33)\end{array}$ & 0.19 & & \\
\hline $\begin{array}{l}\text { PainDETECT total } \\
\text { score }\end{array}$ & $\begin{array}{l}1.14(1.06 \\
\text { to } 1.22)\end{array}$ & $<0.001$ & $\begin{array}{l}1.16(1.08 \\
\text { to } 1.25)\end{array}$ & $<0.001$ \\
\hline $\begin{array}{l}\text { Beck Depression } \\
\text { Inventory }\end{array}$ & $\begin{array}{l}1.01(.97 \\
\text { to } 1.05)\end{array}$ & 0.56 & & \\
\hline $\begin{array}{l}\text { Efficacy of pain } \\
\text { relief }\end{array}$ & $\begin{array}{l}0.86(.71 \\
\text { to } 1.04)\end{array}$ & 0.12 & & \\
\hline Health score & $\begin{array}{l}0.99(.84 \\
\text { to } 1.17)\end{array}$ & 0.92 & & \\
\hline $\begin{array}{l}\text { Current pain } \\
\text { intensity }\end{array}$ & $\begin{array}{l}1.20(1.01 \\
\text { to } 1.41)\end{array}$ & 0.034 & & \\
\hline $\begin{array}{l}\text { FM pain as the } \\
\text { worst current } \\
\text { pain }\end{array}$ & $\begin{array}{l}0.31(.16 \\
\text { to } .62)\end{array}$ & $<0.001$ & $\begin{array}{l}0.25(0.11 \\
\text { to } 0.53)\end{array}$ & $<0.001$ \\
\hline IPAQ & $\begin{array}{l}1.00(1.00 \\
\text { to } 1.00)\end{array}$ & 0.56 & & \\
\hline
\end{tabular}

*Forward selection. Only those variables are shown which entered the model. 
of neuropathic pain was underestimated in our study, neuropathic pain was found in $37 \%$ of the patients. This is about five-fold compared to the prevalence in the general population according to the studies using LANSS [6] and DN4 [7].

It is important to bear the possibility of neuropathic pain in mind when a FM patient complains of sensory symptoms and pain with neuroanatomically plausible distribution. In such cases, careful examination of the patient is needed to support or exclude the diagnosis of neuropathic pain; FM and neuropathic pain are not mutually exclusive. Depending of the location of the pain and findings in the bedside examination, additional test (e.g., electroneuromyography in suspected peripheral nerve lesion, quantitative sensory testing and skin biopsy in suspected small fiber neuropathy, or magnetic resonance imaging in suspected central nervous system lesion) may be indicated (see more detailed report in $[10,18]$ ).

It is generally assumed that the bodily distress disorders are highly associated with emotional distress, e.g., mood disorder. However, according to the BDI results, our patients with and without neuropathic pain had similar level of depressive symptoms.

The limitations of our study are retrospective setting, cross-sectional clinical evaluation, descriptive nature of the study (we were not allowed to perform additional diagnostic procedures to improve the level of certainty of the neuropathic pain diagnosis), secondary health care setting, and ignorance of other pains but FM and neuropathic pain.

Diagnosis of neuropathic pain may give an opportunity for curative treatment of the cause of neuropathic pain (e.g., surgical release of a nerve entrapment). In addition, patients with both FM and neuropathic pain might be favorable candidates for a treatment trial with tricyclic antidepressants, pregabalin or duloxetine, which have proved their efficacy for both conditions [25-27].

\section{Conclusion}

This study highlights the importance of thorough clinical examination when a FM patient emerges with new symptoms. Neuropathic pain screening tools such as PainDETECT are not as useful for FM patients as for other patient. However, if it is used, a positive PainDETECT score still attracts the clinician's attention to the possibility of neuropathic pain and encourages performing an adequate neurological examination and the consideration of further testing when needed.

\section{Competing interests}

The authors do not have any competing interests in this study.

\section{Authors' contributions}

$J \mathrm{G}, \mathrm{HK}$ and $\mathrm{MH}$ conceived of the study and did the statistical analyzes. TH was responsible of clinical examination of participants. JG was responsible of writing the manuscript. $\mathrm{PH}$ contributed to study design. $\mathrm{HK}, \mathrm{PH}$ and $\mathrm{MH}$ critically reviewed the manuscript. All authors read and approved the final manuscript.

\section{Acknowledgements}

The study received financial support from the research funds of Rehabilitation Orton and the Social Insurance Institute of Finland. We appreciate their support for this study.

\section{Author details}

1ORTON Rehabilitation Centre, ORTON Foundation, Helsinki, Finland. ${ }^{2}$ Department of Medicine, Central Finland Central Hospital, Jyväskylä, Finland. ${ }^{3}$ Unit of Family Practice, Central Finland Central Hospital, Jyväskylä, Finland. ${ }^{4}$ Unit of Primary Health Care, Kuopio University Hospital, Kuopio, Finland. ${ }^{5}$ University of Eastern Finland, School of Medicine, Kuopio, Finland. ${ }^{6}$ Etera Mutual Pension Insurance Company, Helsinki, Finland. ${ }^{7}$ Department of Neurosurgery, Helsinki University Central Hospital, Helsinki, Finland.

Received: 14 August 2012 Accepted: 8 February 2013

Published: 14 February 2013

\section{References}

1. White KP, Harth M: Classification, epidemiology and natural history of fibromyalgia. Curr Pain Headache Rep 2001, 5:320-329.

2. Clauw DJ: Fibromyalgia: an overview. Am J Med 2009, 122:3-13.

3. Bigatti SM, Hernandez AM, Cronan TA, Rand KL: Sleep disturbances in fibrmyalgia syndrome: relationship to pain and depression. ArthritisRheum ArthritisCare Res 2008, 59:961-967.

4. Rehm SE, Koroschetz J, Gockel U, Brosz M, Freynhagen R, Tölle TR, Baron R: A cross-sectional survey of 3035 patients with fibromyalgia: subgroups of patients with typical comorbidities and sensory symptom profiles. Rheumatology 2010, 49:1146-1152.

5. Jensen TS, Baron R, Haanpää M, Kalso E, Loeser JD, Rice AS, Treede RD: A new definition of neuropathic pain. Pain 2011, 152:2204-2205.

6. Torrance N, Smith BH, Bennett MI, Lee AJ: The epidemiology of chronic pain of predominantly neuropathic origin. Results from a general population survey. J Pain 2006, 7:281-289.

7. Bouhassira D, Lanteri-Minet $M$, Attal N, Laurent B, Touboul C: Prevalence of chronic pain with neuropathic characteristics in the general population. Pain 2008, 136:380-387.

8. Yawn BP, Wollan PC, Weingarten TN, Watson JC, Hooten WM, Melton LJ 3rd: The prevalence of neuropathic pain: clinical evaluation compared with screening tools in a community population. Pain Med 2009, 10:586-593.

9. Bennett Ml, Attal N, Backonja MM, Baron R, Bouhassira D, Freynhagen R, Scholz J, Tolle T, Wittchen H, Jensen TS: Using screening tools to identify neuropathic pain. Pain 2007, 127:199-203.

10. Haanpää M, Attal N, Backonja M, Baron R, Bennett M, Bouhassira D, Cruccu G, Hansson P, Haythornthwaite J, lannetti G, Jensen T, Kauppila T, Nurmikko T, Rice A, Rowbotham M, Serra J, Sommer C, Smith B, Treede R-F: NeuPSIG guidelines on neuropathic pain assessment. Pain 2011, 152:14-27.

11. Baron R, Tölle TR, Gockel U, Brosz M, Freynhagen R: A cross-sectional cohort survey in 2100 patients with painful diabetic neuropathy and postherpetic neuralgia: differences in demographic data and sensory symptoms. Pain 2009, 146:34-40.

12. Freynhagen $R$, Baron R, Gockel U, Tölle TR: PainDETECT: a new screening questionnaire to identify neuropathic components in patients with back pain. Curr Med Res Opin 2006, 22:1911-1920.

13. Beck AT, Steer RA: Manual of the Beck Depression Inventory. San Antonio Texas: Psychology Corporation; 1988.

14. Burckhardt C, Clark S, Bennet R: The fibromyalgia impact questionnaire: development and validation. J Rheumatol 1991, 18:728-733.

15. Viinamäki H, Tanskanen A, Honkalampi K, Koivumaa-Honkanen H, Haatainen K, Kaustio O, Hintikka J: Is the Beck Depression Inventory suitable for screening major depression in different phases of the disease? Nord $J$ Psychiatry 2004, 58:49-53.

16. Gauffin J, Hankama T, Kautiainen H, Arkela-Kautiainen M, Hannonen P, Haanpää M: Validation of a Finnish version of the Fibromyalgia Impact Questionnaire (Finn-FIQ). Scan J Pain 2012, 3:15-20.

17. Wolfe F, Smythe HA, Yunus MB, Bennet RM, Bombardier C, Goldenberg DL, Tugwell P, Campbell SM, Abeles M, Clark P, Fam AG, Farber SJ, Fiechtner JJ, Franklin CM, Gatter RA, Hamaty D, Lessard J, Lichtbroun AS, Masi AT, McCain GA, Reynolds WJ, Romano TJ, Russel IJ, Sheon RP: The American College of 
Rheumatology 1990 criteria for the classification of fibromyalgia. Report of the multicenter criteria committee. Arthritis Rheum 1990, 33:160-172.

18. Cruccu G, Anand P, Attal N, Garcia-Larrea L, Haanpää M, Jorum E, Serra J, Jensen T: EFNS guidelines on neuropathic pain assessment. Eur J Neurol 2004, 11:153-162.

19. Treede RD, Jensen TS, Campbell JN, Cruccu G, Dostrovsky JO, Griffin JW, Hansson P, Hughes R, Nurmikko T, Serra J: Redefinition of neuropathic pain and a grading system for clinical use: consensus statement on clinical and research diagnostic criteria. Neurology 2008, 70:1630-1635.

20. Bouhassira D, Attal N, Alchaar H, Boureau F, Brochet B, Bruxelle J, Cunin G, Fermanian J, Ginies P, Grun-Overdyking A, Jafari-Schluep H, Lantéri-Minet M, Laurent B, Mick G, Alain S, Valade D, Vicaut E: Comparison of pain syndromes associated with nervous or somatic lesions and development of a new neuropathic pain diagnose questionnaire (DN4). Pain 2005, 114:29-36.

21. Bennett MI: The LANSS Pain Scale: the Leeds assessment of neuropathic symptoms and signs. Pain 2001, 92:147-157.

22. Bouhassira $D$, Attal N: Diagnosis and assessment of neuropathic pain: the saga of clinical tools. Pain 2011, 152(3 Suppl):S74-S83.

23. Koroschetz J, Rehm S, Gockel U, Brosz M, Freynhagen R, Tölle T, Baron R: Fibromyalgia and neuropathic pain - difference and similarities. A comparison of 3057 patients with diabetic painful neuropathy and fibromyalgia. BMC Neurol 2011, 11:55. 25.

24. Martinez-Lavin M, López S, Medina M, Nava A: Use of the Leeds assesment of neuropathic symptoms and signs questionnaire in patients with fibromyalgia. Semin Arthritis Rheum 2003, 32:407-411.

25. Attal N, Cruccu G, Baron R, Haanpää M, Hansson P, Jensen TS, Nurmikko T: EFNS guidelines on the pharmacological treatment of neuropathic pain: 2009 revision. Eur J Neurol 2010, 17:1113-1188.

26. Mease PJ: Further strategies for treating fibromyalgia: the role of serotonin and norepinephrine reuptake inhibitors. Am J Med 2009, 122:44-55.

27. Straube S, Derry S, Moore RA, McQuay HJ: Pregabalin in fibromyalgia: meta-analysis of efficacy and safety from company clinical trial reports. Rheumatology 2010, 49:706-715.

doi:10.1186/1471-2377-13-21

Cite this article as: Gauffin et al:: Neuropathic pain and use of

PainDETECT in patients with fibromyalgia: a cohort study. BMC Neurology 2013 13:21.

\section{Submit your next manuscript to BioMed Central and take full advantage of:}

- Convenient online submission

- Thorough peer review

- No space constraints or color figure charges

- Immediate publication on acceptance

- Inclusion in PubMed, CAS, Scopus and Google Scholar

- Research which is freely available for redistribution 